\title{
Review of Clinical Evidence over 10 Years on Prevention and Treatment of a Film-Forming Medical Device Containing Photolyase in the Management of Field Cancerization in Actinic Keratosis
}

\author{
Susana Puig • Corinne Granger · Aurora Garre · Carles Trullàs • \\ Onofre Sanmartin • Giuseppe Argenziano
}

Received: February 11, 2019 / Published online: April 9, 2019

(C) The Author(s) 2019

\begin{abstract}
Actinic keratosis (AK) is a common pathology that afflicts sun-exposed areas of the skin. It predominantly affects older and fairskinned individuals suggesting an accumulative damage attributable to chronic sun exposure. The prevalence of AK has risen in the past decades and is expected to continue to rise. Apart from visible hyperkeratotic, hyperplastic lesions, AK is also associated with the presence of subclinical lesions adjacent to tumor tissue, which has led to the use of the concept "cancerization field". Although lesion- and field-targeting treatments are currently
\end{abstract}

Enhanced Digital Features To view enhanced digital features for this article go to https://doi.org/10.6084/ m9.figshare.7901618.

Electronic supplementary material The online version of this article (https://doi.org/10.1007/s13555019-0294-1) contains supplementary material, which is available to authorized users.

\section{S. Puig ( $ه)$}

Dermatology Department, Melanoma Unit, Hospital Clínic, Universitat de Barcelona, Barcelona, Spain e-mail: spuig@clinic.cat

S. Puig

Institut d'Investigacions Biomèdiques August Pi i

Sunyer (IDIBAPS), Barcelona, Spain

\section{S. Puig}

Centro de Investigación en Red de Enfermedades Raras (CIBER ER), Instituto de Salud Carlos III, Barcelona, Spain available, many are associated with local side effects and recurrence of new lesions. This review provides information on AK pathophysiology and treatment options and summarizes the available clinical evidence supporting the use of Eryfotona AK-NMSC, a film-forming medical device with SPF $100+$ containing the DNA repair enzyme photolyase, for managing $\mathrm{AK}$, based on the analysis of the results of 228 patients treated with the product.

Funding: ISDIN funded the Article Processing Charges.

Keywords: Actinic keratosis; Confocal microscopy; Dermoscopy; Field cancerization; Melanoma; OCT; Photolyase; Skin cancer; Sunscreen; UVB

C. Granger · A. Garre · C. Trullàs

Innovation and Development, ISDIN, Barcelona, Spain

O. Sanmartin

Department of Dermatology, Fundación Instituto Valenciano de Oncologia, Universidad Católica de Valencia San Vicente Martir, Valencia, Spain

G. Argenziano

Dermatology Unit, Second University of Naples, Nuovo Policlinico (Edificio 9C), Via Pansini 5, 80131 Naples, Italy 


\section{ACTINIC KERATOSIS}

\section{Description, Risk Factors, Epidemiology, and Definition}

Actinic keratosis (AK) represents a common skin disease, clinically characterized by crusty and squamous lesions, usually erythematous but also pigmented, that histologically show several degrees of keratinocytic atypia. The lesion diameter can range from a few millimeters to more than $2 \mathrm{~cm}$ [1]. Lesions are normally located on the chronically sun-exposed areas such as the face, bald scalp, forearms, and back of the hands, primarily in fair-skinned individuals (Fig. 1). The cumulative exposure to solar radiation is the main causative factor of skin damage, as indicated by the name of the disease ("actinic" refers to radiation) $[2,3]$.

In addition to fair skin (Fitzpatrick phototype I-III), other risk factors include advanced age, gender, occupation (outdoor workers are at higher risk), immunosuppression, and genetic predisposition $[3,4]$. The lesions appear as pink, red, or brownish patches, papules, or plaques and are generally asymptomatic, but may also cause itching or be sensitive to touch $[5,6]$. AK most often manifests as multiple lesions rather than a single lesion [7] (Fig. 1). AK lesions are mainly diagnosed by clinical evaluation and confirmed by a histological analysis,

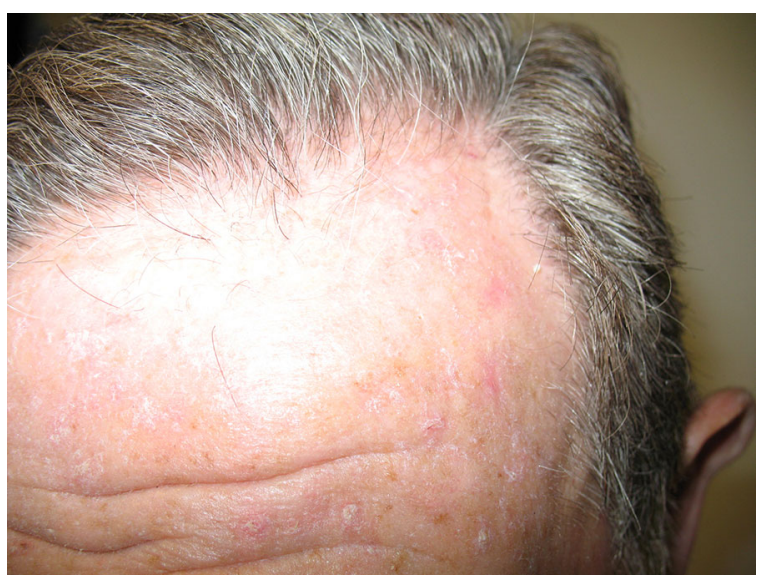

Fig. 1 Lesions observed on the forehead of a patient with $\mathrm{AK}$ and field cancerization dermoscopy, or reflectance confocal microscopy if necessary [1]. AK lesions are classified in grades depending on their severity: grade I, slightly palpable AK; grade II, moderately thick AK; and grade III, very thick and hyperkeratotic lesions [8-10]. AK is considered part of a disease continuum in sun-damaged skin characterized by the proliferation of atypical keratinocytes and represents an important health concern due to its potential to progress to invasive squamous cell carcinoma (SCC), a type of nonmelanoma skin cancer (NMSC) which is associated with considerable morbidity and high metastatic potential $[11,12]$. In fact, recent histological and molecular characterization of $\mathrm{AK}$ and international guidelines on its management support the definition and classification of AK as an in situ SCC $[1,8,9]$. It has been reported that around $5-10 \%$ of AK cases can progress to invasive SCC in a 10-year period $[10,13]$.

The risk for disease progression depends on the number of risk factors and on clinical features [14]. Individuals with more than five AK lesions are at a higher risk of developing SCC and this risk may rise to $20 \%$ for individuals with more than 20 AK lesions $[15,16]$.

The prevalence of the condition varies among reports depending on country and population type. In general, $\mathrm{AK}$ is more frequent among older individuals and men, and in countries closer to the equator. In Europe, a prevalence of up to $38 \%$ has been reported (around 3\% for Germany, 15\% in UK, 23\% for Spain, 38\% for the Netherlands) [17-20] while a prevalence of $11-26 \%$ has been reported in the USA [21]. The highest rates have been reported in Australia where up to $60 \%$ of individuals over the age of 40 are reported to have AK [2, 22, 23].

\section{Histological Characteristics}

The development of AK is associated with clinical, histological, and molecular changes. Histologically, $\mathrm{AK}$ is defined by a mild keratinocytic atypia in the lower layers of the epidermis, resulting in a defective maturation of the superficial epidermis $[1,3,5]$. 
The severity of AK lesions is defined on the basis of the distribution of atypical keratinocytes in the epidermis. Grade I and II AKs, both defined as early in situ SCC, are characterized by the presence of atypical keratinocytes in the lower third and lower two-thirds of the epidermis, respectively. In grade III AK or in situ SCC, atypical keratinocytes are present in more than two-thirds of the epidermis $[8,9]$. It was previously considered that invasive SCC originated according to a progression model from AK I, to AK II, AK III, and finally SCC (Fig. 2). Recently, Fernández-Figueras and co-workers demonstrated that most invasive SCCs are surrounded by AK I tissue, suggesting that the aforementioned progression model is not always accurate [24].

Invasive SCC resembles this histological profile but can be distinguished from $\mathrm{AK}$ by the presence of infiltrative cells that cross the basement membrane between the epidermis and dermis and thus invade the dermis. These cells are not easily detected at an early stage. In this case the thickness of the epidermal atypia and the implication of hair follicles could be an indicator of the invasive nature. In contrast, later stages of invasive SCC are associated with the formation of easily detected nests of atypical tumor cells in the dermis [11].

\section{Pathophysiology}

The exact pathogenic mechanism of $\mathrm{AK}$ is elusive, but it has been widely suggested that the induction of DNA damage by UV radiation is the main trigger of the process. The UV-B spectrum (290-320 nm) can lead to direct DNA damage by inducing the formation of cyclobutane pyrimidine dimers (CPDs) and pyrimidine-pyrimidone 6-4 photoproducts with a subsequent oncogene expression in the entire affected field $[1,9,10]$. Absorption of UV-A radiation (320-400 $\mathrm{nm}$ ) by skin chromophores leads to the generation of reactive oxygen species which oxidize guanine residues in the DNA, thus generating mutagenic oxidative products $[1,9,10]$.

Interestingly, the creation of photoproducts continues for more than $3 \mathrm{~h}$ after UV irradiation in all skin types except in albino patients. These products are known as dark cyclobutene pyrimidine dimers and are caused by the excitation of electrons in melanin (mostly pheomelanin) and melanin fragments [25]. If DNA repair capacity is impaired or defective, the accumulation of oncogenic mutations on actinically damaged skin leads to a proliferation of atypical keratinocytes that may manifest as AK lesions $[2,9]$.

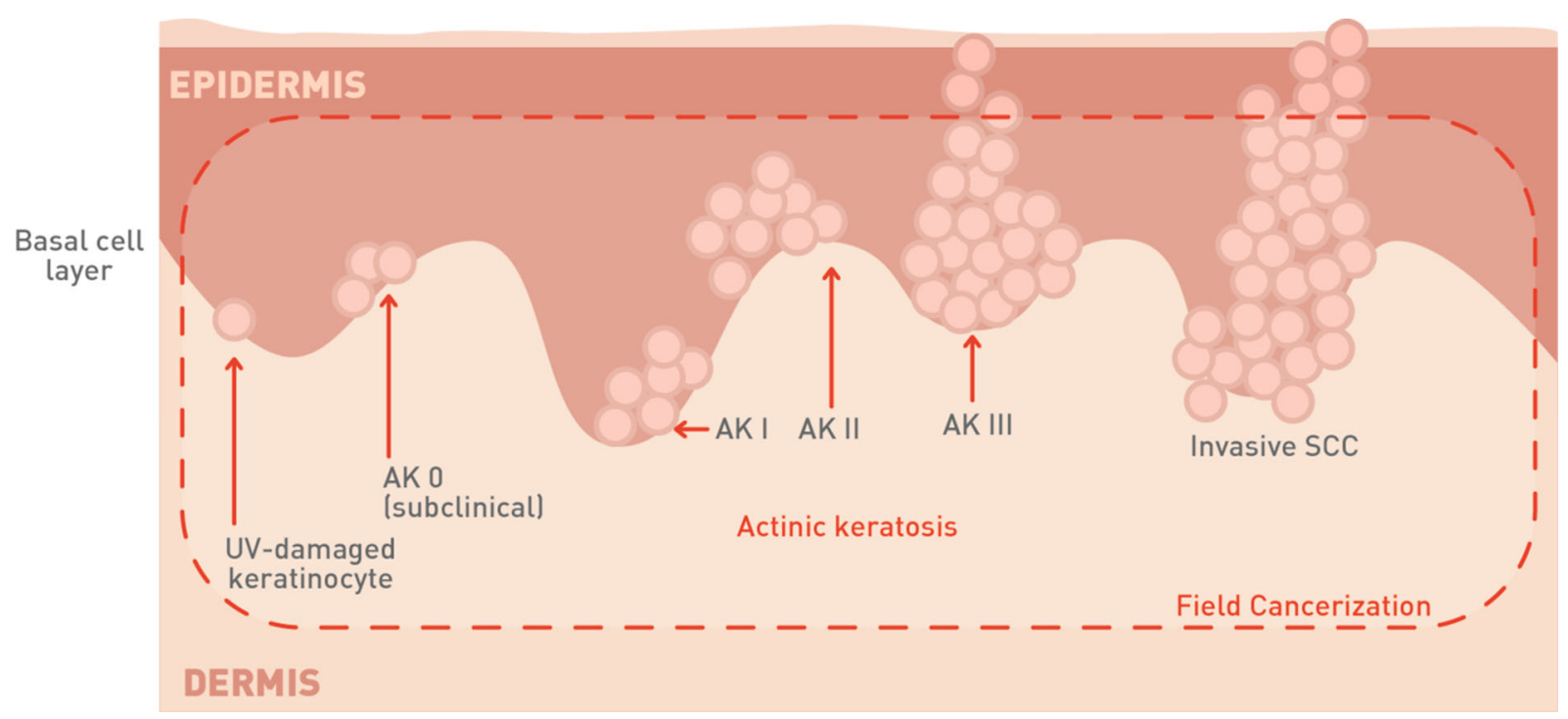

Fig. 2 Schematic representation of AK cancerization field 


\section{Molecular Changes}

At the molecular level, many similarities have been described in AK and SCC [9]. Particularly, a p53 pathway dysregulation has been reported to be crucial for the development of both $\mathrm{AK}$ and SCC lesions [6, 26-28]. $p 53$ plays an essential role in cell cycle arrest, repair of damaged DNA, and tumor suppression. Mutations in this gene affect its role as a cell cycle regulator and also result in the release of cells with damaged DNA from apoptotic control, leading to a clonal expansion of altered keratinocytes into an AK lesion [13].

\section{The Concept of "Cancerization Field"}

UV light causes the initial mutational event in sun-exposed skin area. As a result of accumulated mutations in key genes, loss of cell cycle arrest in certain cells leads to a clonal expansion. In a patient presenting visible AK lesions, multiple non-visible lesions at different stages of progression can be present. The visible clinical lesions represent an initial indication of a disease continuum than can progress from atypical keratinocytes first to asymptomatic AK lesions and then to invasive SCC [29]. Apart from the clinically manifested lesions, subclinical lesions, in the form of dysplastic keratinocytes, can be also observed histologically on a clinically lesion-free skin, surrounding the AK lesions [15].

The number of subclinical lesions in the area can be more than 10 times that of visible lesions [30]. AK lesions at different stages of development, i.e., UV-damaged keratinocytes, subclinical (invisible) lesions, early clinical lesions, late clinical lesions, and even invasive SCC, can coexist at the same time [30]. To reflect this situation, in AK the term "field of cancerization" is often used when describing the condition [31, 32] (Fig. 2). In the case of AK, field cancerization specifically refers to the process whereby keratinocytes surrounding a visible lesion appear histologically normal but are genetically altered [2].

\section{AK Management}

Taking into consideration the global population aging trend and the risk of AK lesions progressing to invasive SCC, the management of AK could become an important public health issue. Clinically and histologically it is very difficult to anticipate which lesions could progress to SCC and therefore treatment of the whole cancerization field is recommended as a preventive measure to reduce actinic damage and the risk for neoplasm progression. Therefore, AK should be treated at the earliest possible stage [33]. To this end, a variety of therapeutic approaches are currently available. Some of them are administered by qualified physicians, while others can be applied topically by patients. Treatment options include lesion- and field-targeted approaches [7]. Summarized information on the most commonly used currently available treatment options is provided in Supplementary Table 1 . Treatment choice depends mainly on the number, size, location, and severity of the lesions.

To provide guidance for treatment choice in a clinical setting, several European and international guidelines for managing AK have been published in the last 10 years [1, 7, 9, 34-40]. The most recent one has been elaborated by the International League of Dermatological Societies in cooperation with the European Dermatology Forum and published in 2015 [9]. These guidelines are based on the evaluation of clinical trials outcomes with highly selective criteria and provide treatment recommendations based on the evidence level of each of the approaches. Some of the most recent guidelines also provide treatment algorithms that recommend therapeutic strategies depending on the subgroups of patients $[7,9,34]$. For single palpable or visible AK lesions cryotherapy is strongly recommended. Methods such as curettage, $0.5 \%$ or 5\% 5-FU (5-fluorouracil), 0.5\% 5-FU + 10\% SA (salicylic acid), $3.75 \%$ or $5 \%$ imiquimod, ingenol mebutate, and photodynamic therapy are also suggested. For multiple AK lesions and field cancerization, first-line treatment options include $0.5 \% 5$-FU, 3.75\% imiquimod, ingenol mebutate, and photodynamic therapy. Moreover, cryotherapy, 3\% diclofenac in 2.5\% HA (hyaluronic acid), 5\% 5-FU, 0.5\% 5FU + 10\% SA, 5\% imiquimod, 2.5\% imiquimod, and laser therapy can also be used. For treating AK lesions in immunocompromised patients, cryotherapy, 
curettage, 5\% 5-FU, 5\% imiquimod, and photodynamic therapy have been suggested [9] (Supplementary Table 1).

The selection of the most appropriate approach in each individual case also depends on patient adherence to treatment and presence of other diseases. AK requires a long-term treatment and combined approaches. Sequential treatments can also be considered [7, 9].

Although most currently available treatment options have shown different degrees of efficacy, many of them are associated with local side effects. On the other hand, $25-75 \%$ of patients need to repeat the treatment 1 year later because of recurrence of the lesions [41]. Supplementary Table 1 shows a summary of the most commonly used treatment approaches for AK.

Therefore, novel treatment options with fewer or no side effects and reduced recurrence would be of great interest in this field and would require continuous updates of current recommendations and subsequent integration into clinical practice. Recently medical device products containing UV filters in combination with photolyase or piroxicam have been developed to be used in the management of $\mathrm{AK}$ $[3,42]$. This category of products differs from common cosmetic sunscreens in that they need an external certification by an independent notified body as it falls within the scope of the European regulation of a medical device.

Recent clinical studies have shown that Eryfotona AK-NMSC (ISDIN, Spain), a film-forming medical device with sun protection factor (SPF) $100+$ and the DNA repair enzyme photolyase, can lead to a significant improvement of visible $\mathrm{AK}$ lesions and the cancerization field, and protect against the appearance of new lesions [3]. The product has been reported to be very well tolerated without causing side effects. Recently Eryfotona AK-NMSC has been included in an adjuvant treatment algorithm developed for various risk levels of AK [2].

\section{ERYFOTONA AK-NMSC}

The product is a film-forming medical device that contains organic and inorganic UVB and
UVA sun filters together with a DNA repair enzyme photolyase entrapped in liposomes.

\section{MECHANISM OF ACTION}

Eryfotona AK-NMSC acts by forming a film on the skin, thus protecting from both UVA and UVB radiation. The content of UVA and UVB filters and the vehicle used confer to the product a broad-spectrum protection and a very high SPF $(100+)$. Eryfotona AK-NMSC also contains the DNA repair enzyme photolyase. This light-activated flavoenzyme derived from the algae Anacystis nidulans is unique in that it utilizes the energy from visible blue light (a process called photoreactivation) to revert CPDs and pyrimidine-pyrimidone (6-4) photoproducts. Similar to the DNA repair enzyme T4 endonuclease, photolyase has been entrapped in $\mathrm{pH}$-sensitive multilamellar liposomes. The liposome encapsulation of DNA repair enzymes such as T4 endonuclease $\mathrm{V}$ and photolyase represents a new delivery system approach that shuttles these biologically active DNA repair enzymes into the epidermis and inside the keratinocytes [43-46]. Topical photolyase restores CPDs faster and more effectively than topical endonuclease [46]. This difference can be attributed to the fact that topical application of photolyase and photoreactivation transiently provides an additional repair system to human cells. UV filters together with photolyase mechanisms contribute to the strengthening of DNA repair and protect DNA from further UV-mediated damage.

Eryfotona AK-NMSC also contains several ingredients with emollient and skin-conditioning functions, which act on dryness, scaling, and erythema associated with chronically UV exposed AK skin.

\section{CLINICAL EVIDENCE OF ERYFOTONA AK-NMSC AFTER 10 YEARS OF MARKETING}

This article is based on previously conducted studies and does not contain any studies with human participants or animals performed by any of the authors. 
Since the launch of Eryfotona in 2008, 11 clinical studies have been conducted assessing the beneficial effect of Eryfotona AK-NMSC on the treatment and prevention of AK lesions and on improvement of the field of cancerization in patients with mild to moderate AK. Taking together the results of the 11 clinical studies involving 228 subjects, there is enough evidence to indicate that the use of Eryfotona AKNMSC is beneficial in AK patients [2] even though the majority of these studies were openlabel and involved small numbers of patients. A summary of these studies is provided in Supplementary Table 2 .

Several researchers have presented the outcomes of studies undertaken during the last 10 years in different congresses and in peer-reviewed journals. In this review, we focused on the effect of Eryfotona AK-NMSC at the cellular, histological, and clinical level. Treatment with Eryfotona AK-NMSC applied either alone or in combination with other therapies has been associated with a reduction in the number of lesions, improvement in macroscopic and microscopic characteristics of lesions, and a reduction in appearance of new lesions.

\section{FIRST CASE REPORTS AND PILOT STUDIES}

Between 2013 and 2015, the first studies were published using different diagnostic techniques in order to demonstrate the benefits of Eryfotona AK-NMSC as a single treatment for patients with AK lesions. Puviani et al. [47] published a series of six case studies showing that Eryfotona AKNMSC for periods of 4 weeks to 2 months is efficient in the treatment of AK lesions and of cancerization field, without side effects. In 2015, the same authors published the outcomes of a pilot, prospective, open-label study with $11 \mathrm{AK}$ patients [48] showing that Eryfotona AK-NMSC treatment for 3 months led to a $75 \%$ reduction in the AK lesion area which was both statistically significant and clinically relevant compared to baseline. The product was well tolerated.

These data are consistent with the results reported by Laino et al. [3] according to which treatment with Eryfotona AK-NMSC for
9 months was effective in reducing the hyperthermic halo around AK lesions in all the 27 patients who completed the study, while in five of them the hyperthermic halo disappeared completely. Hyperthermic halo is defined as the area surrounding a tumor lesion that can be detected by active telethermography and can represent the visible expression of the cancerization field [3].

\section{EVIDENCE OF THE EFFECT OF ERYFOTONA AK-NMSC ON THE IMPROVEMENT OF CUTANEOUS HOMEOSTASIS IN THE FIELD OF CANCERIZATION}

At the same time, studies were carried out to identify which immunological or histochemical markers can reflect the improvement in the field of cancerization after a short treatment period (from 2 to 3 months).

In 2013, Puig-Butillé et al. published a study to evaluate the molecular effects of Eryfotona AK-NMSC on the precancerous field in seven AK patients through histopathological and molecular evaluation [49]. Patients were classified into fast and partial responders and it was shown that there were expression level differences for the CPI-17 gene confirmed by RT-PCR between fast and partial responders both before and after treatment. The authors concluded that 1-month treatment with Eryfotona AK-NMSC improved the field of cancerization and restored normal phenotype in at least a subset of samples, through CPI-17 upregulation.

Following this line of research, Puig et al. published a clinical study evaluating the effects of topical Eryfotona AK-NMSC application on the cancerization field in patients with AK [31]. Thirteen AK patients were instructed to use either Eryfotona AK-NMSC or a comparator containing the same organic and inorganic UVB-UVA filters (SPF 100+) without photolyase. Assessments included clinical, dermoscopic, and reflectance confocal microscopy (RCM) assessments, as well as skin biopsies, before and after the 4-week treatment. The authors reported a clinically evident 
improvement in erythema and scaling with Eryfotona AK-NMSC. Moreover, RCM assessment showed a marked reduction in scaling, detached corneocytes and polygonal nucleated cells in the stratum corneum, an improvement of the atypical honeycomb pattern, and fewer round nucleated cells at the spinous granulous layer with Eryfotona AK-NMSC while no improvement was noted with the comparator product. Histopathological findings indicated that after a 4 -week treatment, $50 \%$ of patients showed complete histological clearance. In other words, in these patients, the epidermal morphology was no longer consistent with a diagnosis of AK. These findings were supported with data from immunohistochemistry obtained from biopsies at baseline vs end of the 4-week treatment showing decreased p21 expression (a pro-apoptotic marker) in suprabasal layers and a trend for reduction in proliferating cell nuclear antigen (PCNA, a marker for proliferation) in the basal layer. The authors suggested that longer follow-up studies with biopsy assessments at 3 or 12 months may allow evaluation of the impact of Eryfotona AK-NMSC on p53 expression.

In agreement with these observations are the results of another clinical study conducted in 2014 by Rstom et al. [50] showing that Eryfotona AK-NMSC contributes to a dermoscopic and histological improvement of AK lesions. This study reported that after Eryfotona AKNMSC application for 4 months, grade I lesions presented less desquamation and an improvement in epidermal pattern.

\section{EVIDENCE OF THE EFFECT OF ERYFOTONA AK-NMSC AS A SINGLE TREATMENT IN SEVERE CASES OF ACTINIC KERATOSIS}

The demonstrated evidence of Eryfotona AKNMSC as a unique treatment in cases of low number of $\mathrm{AK}$ lesions has led to research into whether Eryfotona AK-NMSC can also act on more severe cases of $\mathrm{AK}$, in which patients present many $A K$ lesions either due to genetic background or to a state of immunosuppression due to advanced age or treatment for other conditions.

Giustini et al., in 2014, reported data from a retrospective analysis of the use of Eryfotona AK-NMSC in eight patients diagnosed with xeroderma pigmentosum who as a result of a genetic defect of the DNA repair system have increased rates of $\mathrm{AK}$ and other premalignant and malignant skin lesions. Treatment with Eryfotona AK-NMSC was associated with a $65 \%$ reduction in the appearance of new AK lesions and with $56 \%$ and $100 \%$ reduction in the incidence of new BCC and SCC lesions [51].

Along the same lines, Navarrete-Dechent and Molgó [52] undertook a prospective, singlearm, case series to evaluate the effect of Eryfotona AK-NMSC applied twice daily for 3 months on nine patients with field cancerization and multiple AKs. The study showed an absolute reduction of $76.6 \%$ in the number of $\mathrm{AK}$ lesions, with the mean number of lesions reduced from 13.4 to 3.1 without reported adverse events.

\section{EVIDENCE OF THE EFFECT OF ERYFOTONA AK-NMSC VS VERY HIGH PROTECTION SUNSCREENS AS SINGLE TREATMENT OF AK}

Three studies compared the effect of Eryfotona AK-NMSC to very high protection sunscreens (SPF 50+). The outcomes of the studies show that treatment with Eryfotona AK-NMSC leads to a reduction of the number of new lesions, as well as to a clinical, dermoscopic, and histological improvement of existing lesions.

Moscarella et al. evaluated the effects of a 6-month treatment with Eryfotona AK-NMSC vs sunscreen SPF50+ in a prospective, randomized, parallel, double-blind, pilot study [53]. Fifty patients with at least four AK lesions at the same anatomical photo-exposed area were enrolled and 36 patients completed the study. Patients were instructed to use either product twice daily and were not receiving any other treatment for AK during the study. Clinical evaluation, dermoscopy, and RCM were used to evaluate AK lesions at baseline, after 4 weeks, 3 months, and 6 months of treatment. After 6 months of 
treatment, there was a significant reduction in the mean number of $\mathrm{AK}$ lesions vs baseline in the Eryfotona and sunscreen group; both groups also improved Baseline Severity Index (BSI) and Total Clinical Score (TCS) in the subgroup representing mild AK (less than 10 lesions in target area at baseline). The Eryfotona AK-NMSC arm showed a significant decrease in the number of $\mathrm{AK}$ lesions in the target area and a significant improvement of clinical parameters such as BSI and TCS including mean changes of scaling, erythema, pigmentation, and follicular plugs. Importantly, Eryfotona AK-NMSC was more effective than sunscreen in preventing the appearance of new lesions. This effect was statistically significant 3 months after initiating the treatment and persisted as a strong trend until the end of the study (6 months). In the subgroup of patients with less than 10 lesions, only $14 \%$ of the Eryfotona AK-NMSC-treated patients presented new lesions at the end of the study compared to $54 \%$ of the patients using sunscreen [53].

The results in patients with mild AK confirm that Eryfotona AK-NMSC is a relevant therapy in the management of the cancerization field and offers superior benefits compared to the use of sunscreen alone.

\section{EVIDENCE OF THE EFFECT OF ERYFOTONA AK-NMSC VS VERY HIGH PROTECTION SUNSCREENS AFTER PHOTODYNAMIC THERAPY (PDT)}

In a prospective, parallel, assessor-blinded, twoarm study conducted by Eibenschutz et al., the effect of Eryfotona AK-NMSC vs sunscreen (SPF $50+$ ) was evaluated in $30 \mathrm{AK}$ patients after a successful PDT [54]. Participants were randomly assigned to either Eryfotona AK-NMSC or sunscreen group. Both groups had comparable lesion counts at baseline. Participants were instructed to apply either product in a similar fashion, twice daily for 9 consecutive months. At the end of the 9-month period, the appearance of new lesions in the previously PDTtreated area and the need for another session of
PDT or similar therapy was evaluated. A progressive increase in number of AK lesions was observed in the sunscreen group (mean lesion number of 3.6 at the end of the study in comparison to 0.6 just after the PDT session). In comparison, in the Eryfotona AK-NMSC group a significant reduction of $\mathrm{AK}$ lesions and lack of new lesions were observed (mean lesion number of 1.0 at the end of the study in comparison to 2.0 after the PDT session). In the sunscreen treated group, 15 subjects (86\%) presented new AK lesions during the study either in PDT-treated areas or in new areas. From these, 10 patients $(66 \%)$ needed a new PDT session or a field-targeted treatment, while no patients in the Eryfotona AK-NMSC group needed a new PDT session or another field-targeting treatment.

Overall, it can be concluded that the beneficial effect of Eryfotona AK-NMSC in comparison to very high protection sunscreen is evident in terms of reduction in the number of new and existing lesions and no need for additional PDT or another field-targeted treatment.

\section{EVIDENCE OF THE EFFECT OF ERYFOTONA AK-NMSC IN CONJUNCTION WITH CRYOTHERAPY}

Eryfotona AK-NMSC is also effective in reducing the number of existing and new lesions when applied in combination with cryotherapy.

An observational study conducted by VañoGalván et al. evaluated the effect of Eryfotona AK-NMSC in conjunction with cryotherapy on AKs and cancerization field in 41 patients with at least four clinical AK lesions [55]. The participants applied Eryfotona AK-NMSC twice daily for 6 months, starting on the day following cryotherapy. At the end of the 6-month period, the number of AK lesions decreased in comparison to baseline (a mean number of 9.56 lesions was observed at baseline and 1.51 at 6 months). The effect was better manifested in thin AK lesions (grade I-II lesions as per investigator criterion). 
On the other hand, the mean number of new lesions was 0.27 at the end of the first month and 0.76 at the end of the sixth month, suggesting a possible protective effect on the appearance of new lesions. It has previously been shown that cryotherapy is effective only in $68 \%$ of AK cases. Additionally, $96 \%$ of subjects treated with cryotherapy present new lesions 1 year after completion of treatment [55]. The results of the Vaño-Galván et al. study suggest that Eryfotona AK-NMSC could have a beneficial effect on the cancerization field by reducing the incidence of new lesions following cryotherapy. Although an important limitation of this study is the lack of a control group, these results are of interest as Eryfotona AK-NMSC could potentially represent a good therapeutic strategy allowing more time between cryotherapy sessions in patients with AK.

\section{CONCLUSIONS}

$\mathrm{AK}$ is one of the most common skin diseases and is associated with both visible lesions and cancerization field in chronically sun-exposed skin areas. AK should be managed as early as possible to avoid potential evolution of the lesions in invasive SCC. AK treatment options include both lesion-directed and field-directed procedures.

Clinical evidence published in the last few years supports the beneficial effect of Eryfotona AK-NMSC on AK lesions. Several studies with different degrees of clinical evidence have demonstrated that the application of Eryfotona AK-NMSC twice daily leads to a reduction of the number of existing lesions as well as to a clinical, dermoscopic, and histological improvement of the lesions and cancerization field. Additionally, Eryfotona AK-NMSC prevents the appearance of new lesions. The effect is becoming evident as early as 1 or 2 months of treatment. Importantly, application of Eryfotona AK-NMSC was also shown to be effective after PDT treatment and in combination with cryotherapy which are some of the main approaches for managing AK.

Although most of the studies are open-label, the comparators in the case of double parallel- group pilot studies $[53,54]$ were sunscreen SPF $50+$, the notable clinical improvement of lesions and cancerization field seen in these studies cannot be explained by sunscreen alone.

The studies by Stege et al. [45, 46] demonstrating that in human subjects topical applications of photolyase entrapped in liposomes penetrate the skin and reverse UV-induced CPDs, the pilot study by Puig et al. [31] showing that Eryfotona AK-NMSC improved field cancerization significantly better than a comparator sunscreen SPF $100+$, and the study by Berardesca et al. [56] showing that an SPF 50 sunscreen plus photolyase was more effective than SPF 50 sunscreen alone in reducing UVinduced CPDs support that the clinical effects of Eryfotona AK-NMSC are related to photolyase activity and not simply ascribed to the degree of photoprotection.

In the context of these results, Eryfotona AKNMSC can be considered safe and well tolerated as no adverse events have been reported; it can be considered a promising therapeutic approach to be incorporated into the armamentarium for mild to moderate $\mathrm{AK}$, especially in patients with a low number of lesions in monotherapy.

\section{ACKNOWLEDGEMENTS}

Funding. The research at the Melanoma Unit in Barcelona is partially funded by the Spanish Fondo de Investigaciones Sanitarias Grants PI15/00716 and PI15/00956; CIBER de Enfermedades Raras of the Instituto de Salud Carlos III, Spain, co-financed by the European Development Regional Fund "A way to achieve Europe" ERDF; AGAUR 2017_SGR_1134 of the Catalan Government, Spain; the European Commission under the 6th Framework Programme, Contract No. LSHC-CT-2006-018702 (GenoMEL) and by the European Commission under the 7th Framework Programme, Diagnoptics; The National Cancer Institute (NCI) of the US National Institute of Health (NIH) (CA83115); a Grant from "Fundació La Marató de TV3" 201331-30, Catalonia, Spain; a Grant from "Fundación Científica de la 
Asociación Española Contra el Cáncer" GCB15152978SOEN, Spain, and the CERCA Programme/Generalitat de Catalunya. Article processing charges were funded by ISDIN.

Medical Writing and/or Editorial Assistance. An external medical writer/editor (Jane Marshall, freelance) assisted with a limited review and was funded by ISDIN. The authors designed the content and structure and drafted and reviewed the manuscript.

Authorship. All named authors meet the International Committee of Medical Journal Editors (ICMJE) criteria for authorship for this article, had full access to the articles reviewed in the manuscript, and take complete responsibility for the integrity and accuracy of the manuscript.

Disclosures. Susana Puig has been a member of the Advisory board of ISDIN since 2016. C Granger is an employee of ISDIN. A Garre is an employee of ISDIN. C Trullàs is an employee of ISDIN. O Sanmartin and G Argenziano have nothing to disclose.

Compliance with Ethics Guidelines. This article does not contain any studies with human participants or animals performed by any of the authors.

Open Access. This article is distributed under the terms of the Creative Commons Attribution-NonCommercial 4.0 International License (http://creativecommons.org/licenses/ by-nc/4.0/), which permits any noncommercial use, distribution, and reproduction in any medium, provided you give appropriate credit to the original author(s) and the source, provide a link to the Creative Commons license, and indicate if changes were made.

\section{REFERENCES}

1. Stockfleth E, Kerl H, Guideline Subcommittee of the European Dermatology Forum. Guidelines for the management of actinic keratoses. Eur J Dermatol. 2006;16(6):599-606.
2. Krutmann J, Berking C, Berneburg M, Diepgen TL, Dirschka T, Szeimies M. New strategies in the prevention of actinic keratosis: a critical review. Skin Pharmacol Physiol. 2015;28(6):281-9.

3. Laino L, Elia F, Desiderio F, et al. The efficacy of a photolyase-based device on the cancerization field: a clinical and thermographic study. J Exp Clin Cancer Res. 2015;34(1):84.

4. Naldi L, Chatenoud L, Piccitto R, et al. Prevalence of actinic keratoses and associated factors in a representative sample of the Italian adult population: Results from the Prevalence of Actinic Keratoses Italian Study, 2003-2004. Arch Dermatol. 2006;142(6):722-6.

5. Ceilley RI, Jorizzo JL. Current issues in the management of actinic keratosis. J Am Acad Dermatol. 2013;68(1 Suppl 1):S28-38.

6. Roewert-Huber J, Stockfleth E, Kerl H. Pathology and pathobiology of actinic (solar) keratosis-an update. Br J Dermatol. 2007;157(Suppl 2):18-20.

7. Dréno B, Amici JM, Basset-Seguin N, et al. Management of actinic keratosis: a practical report and treatment algorithm from AKTeam ${ }^{\mathrm{TM}}$ expert clinicians. J Eur Acad Dermatol Venereol. 2014;28(9):1141-9.

8. Roewert-Huber J, Patel MJ, Forschner T, et al. Actinic keratosis is an early in situ squamous cell carcinoma: a proposal for reclassification. $\mathrm{Br} \mathrm{J}$ Dermatol. 2007;156(Suppl 3):8-12.

9. Werner RN, Stockfleth E, Connolly SM, et al. Evidence- and consensus-based (S3) guidelines for the treatment of actinic keratosis-International League of Dermatological Societies in cooperation with the European Dermatology Forum-Short version. $\mathrm{J}$ Eur Acad Dermatol Venereol. 2015;29(11):2069-79.

10. Rossi R, Mori M, Lotti T. Actinic keratosis. Int J Dermatol. 2007;46(9):895-904.

11. Yanofsky VR, Mercer SE, Phelps RG. Histopathological variants of cutaneous squamous cell carcinoma: a review. J Skin Cancer. 2011;2011:210813.

12. Trakatelli M, Ulrich C, del Marmol V, Euvrard S, Stockfleth E, Abeni D. Epidemiology of nonmelanoma skin cancer (NMSC) in Europe: accurate and comparable data are needed for effective public health monitoring and interventions. Br J Dermatol. 2007;156(Suppl 3):1-7.

13. Anwar J, Wrone DA, Kimyai-Asadi A, Alam M. The development of actinic keratosis into invasive squamous cell carcinoma: evidence and evolving 
classification schemes. Clin Dermatol. 2004;22(3):189-96.

14. Lalji A, Khiroya N, Lalji M. Actinic keratosis and squamous cell carcinoma. Clin Res Dermatol Open. 2014;1(1):1-3.

15. Emre S. Actinic keratosis and field cancerization. World J Dermatol. 2016;5(2):115-24.

16. Green A, Battistutta D. Incidence and determinants of skin cancer in a high-risk Australian population. Int J Cancer. 1990;46(3):356-61.

17. Schaefer I, Augustin M, Spehr C, Reusch M, Kornek T. Prevalence and risk factors of actinic keratoses in Germany-analysis of multisource data. J Eur Acad Dermatol Venereol. 2014;28(3):309-13.

18. Memon AA, Tomenson JA, Bothwell J, Friedmann PS. Prevalence of solar damage and actinic keratosis in a Merseyside population. $\mathrm{Br} \mathrm{J}$ Dermatol. 2000;142(6):1154-9.

19. Ferrándiz C, Plazas MJ, Sabaté M, Palomino R, EPIQA Study Group. Prevalence of actinic keratosis among dermatology outpatients in Spain. Actas Dermosifiliogr. 2016;107(8):674-80.

20. Flohil SC, van der Leest RJ, Dowlatshahi EA, Hofman A, de Vries E, Nijsten T. Prevalence of actinic keratosis and its risk factors in the general population: the Rotterdam Study. J Invest Dermatol. 2013;133(8):1971-8.

21. Salasche SJ. Epidemiology of actinic keratoses and squamous cell carcinoma. J Am Acad Dermatol. 2000;42(1 Suppl 2):4-7.

22. Frost CA, Green AC, Williams GM. The prevalence and determinants of solar keratoses at a subtropical latitude (Queensland, Australia). Br J Dermatol. 1998;139(6):1033-9.

23. Frost C, Williams G, Green A. High incidence and regression rates of solar keratoses in a Queensland community. J Invest Dermatol. 2000;115(2):273-7.

24. Fernández-Figueras MT, Carrato C, Sáenz X, et al. Actinic keratosis with atypical basal cells (AK I) is the most common lesion associated with invasive squamous cell carcinoma of the skin. J Eur Acad Dermatol Venereol. 2015;29(5):991-7.

25. Premi S, Wallisch S, Mano CM, et al. Photochemistry. Chemiexcitation of melanin derivatives induces DNA photoproducts long after UV exposure. Science. 2015;347(6224):842-7.

26. Torezan LA, Festa-Neto C. Cutaneous field cancerization: clinical, histopathological and therapeutic aspects. An Bras Dermatol. 2013;88(5):775-86.
27. Szeimies RM, Torezan L, Niwa A, et al. Clinical, histopathological and immunohistochemical assessment of human skin field cancerization before and after photodynamic therapy. Br J Dermatol. 2012;167(1):150-9.

28. Chai H, Brown RE. Field effect in cancer-an update. Ann Clin Lab Sci. 2009;39(4):331-7.

29. Malvehy J. A new vision of actinic keratosis beyond visible clinical lesions. J Eur Acad Dermatol Venereol. 2015;29(Suppl 1):3-8.

30. Malvehy J, Roldán-Marín R, Iglesias-García P, Díaz A, Puig S. Monitoring treatment of field cancerisation with $3 \%$ diclofenac sodium $2.5 \%$ hyaluronic acid by reflectance confocal microscopy: a histologic correlation. Acta Derm Venereol. 2015;95(1):45-50.

31. Puig S, Puig-Butillé JA, Díaz MA, Trullas C, Malvehy J. Field cancerisation improvement with topical application of a film-forming medical device containing photolyase and UV filters in patients with actinic keratosis, a pilot study. J Clin Exp Dermatol Res. 2014;5:3.

32. Stockfleth E. Actinic keratosis and field cancerisation. Eur J Dermatol. 2011;21(Suppl 1):3-12.

33. Zalaudek I, Piana S, Moscarella E, et al. Morphologic grading and treatment of facial actinic keratosis. Clin Dermatol. 2014;32(1):80-7.

34. Rossi R, Calzavara-Pinton PG, Giannetti A, et al. Italian guidelines and therapeutic algorithm for actinic keratoses. G Ital Dermatol Venereol. 2009;144(6):713-23.

35. Bonerandi JJ, Beauvillain C, Caquant L, et al. Guidelines for the diagnosis and treatment of cutaneous squamous cell carcinoma and precursor lesions. J Eur Acad Dermatol Venereol. 2011;25(Suppl 5):1-51.

36. Stockfleth E, Ferrandiz C, Grob JJ, et al. Development of a treatment algorithm for actinic keratoses: a European consensus. Eur J Dermatol. 2008;18(6):651-9.

37. Nashan D, Meiss F, Müller M. Therapeutic strategies for actinic keratoses-a systematic review. Eur J Dermatol. 2013;23(1):14-32.

38. de Berker D, McGregor JM, Hughes BR, British Association of Dermatologists Therapy. Guidelines and Audit Subcommittee Guidelines for the management of actinic keratoses. $\mathrm{Br} \mathrm{J}$ Dermatol. 2007;156(2):222-30.

39. Point K. Clinical Practice Guide: Basal cell carcinoma, squamous cell carcinoma (and related 
lesions) - a guide to clinical management in Australia. Sydney: Cancer Council Australia and Australian Cancer Network; 2008.

40. Drake LA, Ceilley RI, Cornelison RL, et al. Guidelines of care for actinic keratoses. Committee on Guidelines of Care. J Am Acad Dermatol. 1995;32(1):95-8.

41. Krawtchenko N, Roewert-Huber J, Ulrich M, Mann I, Sterry W, Stockfleth E. A randomised study of topical 5\% imiquimod vs. topical 5-fluorouracil vs. cryosurgery in immunocompetent patients with actinic keratoses: a comparison of clinical and histological outcomes including 1-year follow-up. Br J Dermatol. 2007;157(Suppl 2):34-40.

42. Puviani M, Galloni C, Marhetti S, et al. Efficacy of a film-forming medical device containing sunscreen $(50+)$ and piroxicam $0.8 \%$ in actinic keratosis and field cancerization: a multicenter, assessor-blinded, 3 month trial. Curr Med Res Opin. 2017;33(7):1255-9.

43. Ceccoli J, Rosales N, Tsimis J, Yarosh DB. Encapsulation of the UV-DNA repair enzyme T4 endonuclease $\mathrm{V}$ in liposomes and delivery to human cells. J Invest Dermatol. 1989;93(2):190-4.

44. Yarosh D, Bucana C, Cox P, Alas L, Kibitel J, Kripke M. Localization of liposomes containing a DNA repair enzyme in murine skin. J Invest Dermatol. 1994;103(4):461-8.

45. Stege H, Roza L, Vink AA, et al. Enzyme plus light therapy to repair DNA damage in ultraviolet-B-irradiated human skin. Proc Natl Acad Sci USA. 2000;97:1790-5.

46. Stege H. Effect of xenogenic repair enzymes on photoimmunology and photocarcinogenesis. J Photochem Photobiol B. 2001;65:105-8.

47. Puviani M, Barcella A, Milani M. Efficacy of a photolyase-based device in the treatment of cancerization field in patients with actinic keratosis and nonmelanoma skin cancer. G Ital Dermatol Venereol. 2013;148(6):693-8.

48. Puviani M, Milani M. A Pilot, prospective, openlabel study on the effects of a topical photorepair and photoprotection film-forming medical device in patients with actinic keratoses evaluated by means of skin analysis camera antera 3D. J Clin Exp Dermatol Res. 2015;6(263):2.
49. Puig-Butillé JA, Malvehy J, Potrony M, et al. Role of CPI-17 in restoring skin homoeostasis in cutaneous field of cancerization: effects of topical application of a film-forming medical device containing photolyase and UV filters. Exp Dermatol. 2013;22(7):494-6.

50. Rstom SA, Abdalla BM, Rezze GG, Paschoal FM. Evaluation of the effects of a cream containing liposomeencapsulated photo lyase and SPF 100 sunscreen on facial actinic keratosis: clinical, dermoscopic, and confocal microscopy based analysis. Surg Cosmet Dermatol. 2014;6(3):226-31.

51. Giustini S, Miraglia E, Berardesca E, Milani M, Calvieri S. Preventive long-term effects of a topical film-forming medical device with ultra-high UV protection filters and dna repair enzyme in xeroderma pigmentosum: a retrospective study of eight cases. Case Rep Dermatol. 2014;6(3):222-6.

52. Navarrete-Dechent C, Molgó M. The use of a sunscreen containing DNA photolyase in the treatment of patients with field cancerization and multiple actinic keratosis: a case series. Dermatol Online J. 2017;23(1):1-3.

53. Moscarella E, Argenziano G, Longo C, Aladren S. Management of cancerization field with a medical device containing photolyase: a randomized, double-blind, parallel-group pilot study. J Eur Acad Dermatol Venereol. 2017;31(9):e401-3.

54. Eibenschutz L, Silipo V, De Simone P, et al. A 9-month, randomized, assessor-blinded, parallelgroup study to evaluate clinical effects of filmforming medical devices containing photolyase and sun filters in the treatment of field cancerization compared with sunscreen in patients after successful photodynamic therapy for actinic keratosis. Br J Dermatol. 2016;175(6):1391-3.

55. Vaño-Galván S, Jiménez N, Grillo E, Ballester A. An observational study on the effectiveness and safety of the combination of a topical product containing photolyase and cryotherapy in patients with actinic keratoses in clinical practice (article in Spanish). Piel. 2016;31(8):532-6.

56. Berardesca E, Bertona $\mathrm{M}$, Altabas $\mathrm{K}$, Altabas V, Emanuele E. Reduced ultraviolet-induced DNA damage and apoptosis in human skin with topical application of a photolyase-containing DNA repair enzyme cream: clues to skin cancer prevention. Mol Med Rep. 2012;5:570-4. 